\title{
EDUCAÇÃO A DISTÂNCIA OU EDUCAÇÃO DISTANTE? O PROGRAMA UNIVERSIDADE ABERTA DO BRASIL, O TUTOR E O PROFESSOR VIRTUAL
}

\author{
ANTONIO A. S. Zuin
}

Mas onde há perigo, cresce também o que salva.

(Hölderlin, 1991)

\begin{abstract}
RESUMO: Atualmente, são várias as questôes que surgem diante da possibilidade de utilização das mediações tecnológicas para o desenvolvimento do processo educacional/formativo dos profissionais da área da educação, a saber: De que modo tais mediações podem ser empregadas em tal processo? Como se desenvolve a relação entre autoridade pedagógica e autoritarismo num ambiente de aprendizagem virtual? Propõe-se, como objetivo deste artigo, refletir sobre tais questôes por meio da análise do programa Universidade Aberta do Brasil, principalmente no que concerne ao papel do tutor e do professor "virtual" no processo educacional/formativo de futuros profissionais formados a distância.
\end{abstract}

Palavras-chave: Educação a distância. Indústria cultural. Universidade Aberta do Brasil. Professor virtual.

DisTANCE EDUCATION OR DISTANT EDUCATION?

The Program "Open University of BraziL“, THE tutor AND THE VIRTUAL TEACHER

ABSTRACT: Using technological resources to develop the educational process of professionals in the area of education currently raises a few questions as: How can these resources be used in the process? How does the relation between pedagogical authority and authoritarianism develop in an environment of virtual learning? This

* Pós-doutor pela Universidade de Leipzig (Alemanha) e professor-adjunto do Departamento de Educação da Universidade Federal de São Carlos (UFSCAR).E-mail: dazu@power.ufscar.br

Educ. Soc., Campinas, vol. 27, n. 96 - Especial, p. 935-954, out. 2006

Disponível em <http://www.cedes.unicamp.br> 
Educação a distância ou Educação distante? O Programa Universidade Aberta...

paper aims at pondering these questions through an analysis of the program "Open University of Brazil" mainly focused on the role of the tutor and of the so called "virtual teachers" in the educational process of these future distance-trained professionals.

Key words: Distance education. Cultural industry. Open University of Brazil. Virtual teacher.

\section{Introdução}

(C)

$\mathrm{O}$

homens passarão e a ciência permanecerá". Os dizeres desta epígrafe da primeira edição do Novum organum, de Francis Bacon (1973), já anunciavam, premonitoriamente, o espírito que predominaria séculos depois na sociedade capitalista transnacional. A valorização da produção científica, que sepultaria, de uma vez por todas, as controvérsias provenientes do "inconsistente" discurso da metafísica, demarcava a fase embrionária do fetiche que apartaria a ciência, como se fosse um ser em si, dos indivíduos responsáveis por sua produção. Ademais, tal consideração sobre a produção científica ilustrava também o quão descartáveis as mercadorias se tornariam e, em especial, a mercadoria humana. Mas talvez nem mesmo o filósofo inglês suspeitasse da aceitação que tal máxima teria na atual sociedade, que erige a produção científica como a menina de seus olhos.

Desde a revolução técnico-científica, ou seja, desde o momento em que o controle da ciência se metamorfoseou na mola propulsora do capitalismo monopolista, na transição do século 19 para o 20 , já se percebera que a participação da universidade seria decisiva para o desenvolvimento do progresso tecnológico. $\mathrm{O}$ caso da Alemanha é exemplar. Unificada tardiamente, em comparação com a França, a Alemanha se transformou numa potência industrializada em decorrência do capitalismo alemão ter criado

(...) aquele esforço total e integrado que organizava, nas universidades, laboratórios industriais, sociedades profissionais e associaçōes comerciais, bem como na pesquisa sob patrocínio governamental, um esforço científico-tecnológico continuado como a nova base para a indústria moderna. (Braverman, 1987, p. 143)

Já nos atuais tempos de capitalismo transnacional, nos quais a chamada especialização flexível (Sennett, 2004, p. 53) exige mudanças 
no processo educacional/formativo, de tal modo que capacitem o trabalhador a adquirir habilidades necessárias para acompanhar a velocidade das inovações tecnológicas, recrudesce, concomitantemente, a preocupação dos governos que representam países de um baixo índice de estudantes universitários formados, tal como no caso do Brasil. É neste contexto que se insere o escopo do governo brasileiro de criar o programa Universidade Aberta do Brasil e os cursos de formação universitária a distância, tais como os cursos de pedagogia e de administração.

São várias as questões que pululam diante da possibilidade de utilização das mediaçôes tecnológicas para o desenvolvimento do processo educacional/formativo dos profissionais da área da educação, a saber: De que modo tais mediações podem ser empregadas neste processo? Que tipos de facilidades e dificuldades são geradas num ambiente de educação a distância? A denominada educação a distância não corre o risco de se afastar de seus objetivos iniciais de promover uma maior aproximação entre os agentes educacionais, na medida em que se converte no fetiche de si mesma? Propõe-se, como objetivo deste artigo, refletir sobre tais questões, partindo-se da premissa de que tais mediações tecnológicas são produtos do trabalho humano, fato este que impinge a necessidade de se realizar uma análise histórico-filosófica a respeito do papel dos chamados tutores e professores virtuais no processo educacional/formativo de futuros profissionais das mais diversas áreas de conhecimento.

\section{O processo educacional/formativo e as comunicaçôes primária e secundária}

Na história do desenvolvimento do modo de produção capitalista, nota-se que a universalização da cidadania se entrelaça com a disseminação do processo educacional/formativo. Pela primeira vez na história da humanidade, o conceito de cidadania seria totalmente universalizado, pois se fundamentaria na formação individual de cada cidadão. Theodor W. Adorno relaciona o conceito de formação com a ascensão da burguesia da seguinte maneira:

O conceito de formação emancipou-se com a burguesia (...). Sua realização deveria corresponder a uma sociedade burguesa de seres livres e iguais (...). A formação era tida como condição implícita a uma sociedade autônoma: quanto mais lúcido o singular, mais lúcido o todo. (Adorno, 1996, p. 391)

Educ. Soc., Campinas, vol. 27, n. 96 - Especial, p. 935-954, out. 2006

Disponível em <http://www.cedes.unicamp.br> 
Educação a distância ou Educação distante? O Programa Universidade Aberta...

A lucidez da sociedade sempre esteve condicionada à lucidez do indivíduo no modo de produção capitalista. A condição básica de uma sociedade autônoma seria a de ser constituída por cidadãos que confiassem no cumprimento do contrato social do capitalismo liberal, uma vez que a garantia do difícil equilíbrio do jogo de forças entre direitos e deveres seria fornecida pelos mesmos cidadãos que se sentiram partícipes efetivos do processo de elaboração de tais normas.

A ideologia liberal sempre apregoou que o progresso na escala hierárquica dependeria da vontade e do livre-arbítrio de cada indivíduo, pois não haveria mais quaisquer tipos de impedimentos, concernentes às opçóes políticas ou mesmo religiosas, que pudessem prejudicar de antemão a possibilidade de ascensão social. A mudança na escala hierárquica não seria mais uma exceção, tal como no feudalismo, cuja estrutura social era tão estanque que a chance de se progredir na vida, para os filhos dos servos e camponeses, limitava-se aos poucos "felizardos" que conseguiam ingressar na "carreira" eclesiástica. O progresso das forças produtivas capitalistas não poderia mais ser conivente com a manutenção desta estrutura sócio-política. Neste contexto, o desenvolvimento das chamadas escolas de massa tornouse peça-chave não só para a assimilação de conhecimentos que seriam exigidos nos futuros postos de trabalho, tais como o aprendizado de noções de álgebra, geometria e da gramática da língua vernácula, como também dos valores que deveriam ser internalizados para a manutenção do capitalismo, tais como pontualidade, disciplina e subserviência. É no final do século 18 que o iluminismo alemão objetiva, de forma paradigmática, a aspiração de que a personalidade autônoma alicerçaria as bases de uma sociedade lúcida. Refiro-me ao texto de Kant: "Resposta à pergunta: que é Esclarecimento?". A definição do conceito de Esclarecimento suscita, de imediato, a realização de um ato de resistência, pois o

Esclarecimento (Aufklārung) é a saida do homem de sua menoridade, da qual ele próprio é culpado. A menoridade é a incapacidade de fazer uso de seu entendimento sem a direção de outro indivíduo. O homem é o próprio culpado dessa menoridade se a causa dela não se encontra na falta de entendimento, mas na falta de decisão e de coragem de servir-se de si mesmo sem a direção de outrem. Sapere Aude! Tem coragem de fazer uso de teu próprio entendimento, tal é o lema do Esclarecimento. (Kant, 1985, p. 100) 
Para Kant, a comodidade de ser menor se esteia na entrega aos mandos e desmandos explícitos, ou mais sutis, dos tutores que traçam de antemão as diretrizes dos caminhos percorridos pelos tutelados. $\mathrm{Na}$ quele período histórico, a verve crítica do filósofo alemão focava a figura do conhecido opositor do Esclarecimento: a Igreja. Com efeito, já Descartes e Galileu, só para lembrar alguns nomes, solaparam as bases do edifício do saber engendrado pela Igreja que obstaculizava o devir do conhecimento científico. De certa forma, tanto Descartes quanto Galileu defenderam o ousar saber contra os óbices impostos pela Igreja, o tutor então hegemônico. Já para Kant, tal definição do significado do Esclarecimento implicava diretamente o reconhecimento de seus limites, pois certas restrições sociais poderiam, paradoxalmente, auxiliar o progresso da Aufklärung. Se o indivíduo letrado, ao fazer o uso privado de sua razão, tem que se submeter aos imperativos impostos quando se encontra na condição de pertencer a alguma instituição, tais como o exército ou a Igreja, ele, na condição de cidadão do mundo, pode e deve fazer uso público de sua razão. E, ao fazer tal uso, este indivíduo adquire a prerrogativa de contestar as normas de seus tutores com o objetivo de aprimorar as regras que tem que respeitar no seu estado de membro do exército ou da Igreja. É neste sentido que o reconhecimento dos limites do Esclarecimento pode proporcionar a superação (Aufhebung) da condição de menoridade, pois o indivíduo se transforma no cidadão que tem consciência da força de sua intervenção naquele jogo estabelecido entre o cumprimento dos seus direitos e seus deveres.

Ora, se a destruição da tutoria da Igreja pôde ser arquitetada na dimensão do idealismo kantiano, seria fundamental que as condições materiais, originadas pelo capitalismo em sua fase revolucionária, possibilitassem a difusão maciça dos germens do Esclarecimento. Para Neil Postman, o processo de alfabetização em massa, além de contribuir para tal difusão, também delineia os traços divisórios entre a infância e a idade adulta:

A leitura é o flagelo da infância porque, em certo sentido, cria a idade adulta (...). Num mundo letrado, as crianças precisam transformar-se em adultos. Entretanto, num mundo não letrado não há necessidade de distinguir com exatidão a criança e o adulto, pois existem poucos segredos e a cultura não precisa ministrar instrução sobre como entendê-la. (Postman, 2005, p. 27) 
Educação a distância ou Educação distante? O Programa Universidade Aberta...

A idade adulta se metamorfoseia num vir a ser e delineia, consequentemente, as nuances de seu oposto, ou seja, a infância. Os conhecimentos que distinguem a fase adulta serão desvendados gradativamente e delimitarão as vicissitudes das fases que a antecedem. Mas o que se pode asseverar de um período da história da humanidade no qual praticamente não existem mais segredos? Os atuais meios de comunicação de massa bombardeiam-nos com estímulos e informações que, em muitas ocasióes, se amalgamam em verdadeiros choques audiovisuais. Para Postman, isto significa o desaparecimento da infância, ao menos daquela noção de infância idealizada pela burguesia ascendente econômica e politicamente. Entre os recém-nascidos e os senis, existe um híbrido de adulto-criança e de criança-adulto que é resultado de uma era de hegemonia de imagens que estimulam a disseminação de um raciocínio estereotipado e fragmentado. Se, por um lado, a criança se "adultifica" ao ser considerada (e ao se considerar!) um consumidor como outro qualquer, por outro, o adulto se infantiliza quando seu narcisismo e seu sentimento de onipotência são insuflados pelos dizeres das propagandas veiculadas pela televisão, as quais prometem a realização imediata do desejo, desde que o produto associado também seja adquirido.

O desenvolvimento do poder da comunicação elétrica provocou abalos sísmicos não "apenas" nas linhas tênues estabelecidas entre a infância e a idade adulta, mas também nas relações espaço-temporais. $\mathrm{O}$ telégrafo "eliminou de uma tacada o tempo e o espaço como condições da comunicação humana e, portanto, descarnou a informação a um ponto tal que superou de longe a palavra escrita e a imprensa" (idem, ibid., p. 84). De fato, pela primeira vez na história da humanidade a velocidade da transmissão da mensagem superou a velocidade do corpo humano ou dos animais utilizados para levar as informações de um lado para o outro. Desde então, parece fazer cada vez mais sentido a expressão vergonha prometêutica. Numa referência ao mito de Prometeu, Günther Anders observa que o ser humano se incomoda em "apresentar, diante dos olhos dos aparelhos perfeitos, sua patética condição de ser carnal, a imprecisão de sua condição humana. $\mathrm{Na}$ verdade, ele tinha mesmo que se envergonhar diante disso" (Anders, 2002, p. 23). Ora, se a vergonha diante da perfeição da máquina pode engendrar a auto-reflexão crítica sobre a fragilidade daquele que a criou, esta mesma vergonha também pode provocar a inveja do criador, que não se contenta com o alento de ser um deus ex machina, mas anseia mimetizar a força da máquina convertida em 
fetiche para que ele próprio seja identificado e se reconheça como máquina. Não é fortuito o jargão dos adolescentes de que querem transformar seu corpo numa máquina perfeita, mesmo que para isso tenham que praticar exercícios físicos à exaustão nas academias de ginástica.

A intensificação de tal consciência reificada não pode ser imputada exclusivamente às características idiossincráticas de tais jovens, mas deve ser compreendida como manifestação de um determinado espírito objetivo de um tempo, ou seja, de uma cultura. A mesma cultura que produz indivíduos solitariamente "conectados", por meio do maquinário tecnológico que realiza a comunicação on line. A possibilidade da comunicação instantânea e em tempo real incita o aparecimento do seguinte questionamento: Afinal, o que as pessoas têm para comunicar quando se "conectam"? Será que, em geral, tais pessoas compartilham efetivamente suas incertezas e dramas pessoais, de tal modo que amainam, na medida do possível, o isolamento e a dessensibilização com o auxílio dos meios de comunicação, os quais foram criados justamente para apartar ou, ao menos, dirimir tal solidão? Esta não parece ser a característica predominante dos "relacionamentos" que vicejam nas comunidades virtuais, ainda mais na sociedade na qual a frieza logra a condição de caráter normativo ao se universalizar como uma forma de percepção (Gruschka , 1994, p. 35). Assim, a mera utilização dos recursos audiovisuais mais refinados não significa, aprioristicamente, que as pessoas se comunicam e que, portanto, possam expressar os problemas concernentes à própria privação. Neste estado, o processo de comunicação não é um nada, mas também ainda não se objetivou efetivamente, daí o sentido etimológico da palavra virtual.

Porém, a condição de possibilidade que se encontra subjacente à palavra virtual se concretiza, atualmente, no fetiche de que a comunicação secundária, ou seja, a comunicação mediada pelos aparelhos técnicos, torna-se hegemônica em relação à primária, realizada presencialmente. De acordo com Türcke (2002, p. 297),

A proximidade, instituída por tais aparelhos, consiste meramente numa superação de distâncias espaço-temporais, redução e aceleração ao máximo dos limitados processos de comunicação, e isto não pode ser confundido com "proximidade humana" no sentido da participação mútua e da identificação, que só podem ser gradativamente construídas ao longo do convívio mútuo e da troca de experiências. E para isto necessita-se, o mais urgentemente possível, daquilo que as novas tecnologias desejam economizar ao máximo: tempo.

Educ. Soc., Campinas, vol. 27, n. 96 - Especial, p. 935-954, out. 2006

Disponível em <http://www.cedes.unicamp.br> 
A economia do tempo é desejada na sociedade que prioriza a economia dos "desperdícios" gerados das tensōes e alegrias que compóem o tecido das relaçóes humanas. Quando o mundo das mercadorias se vê inundado por um fluxo de informaçóes imediato, contínuo e ininterrupto, tal como ocorre no capitalismo transnacional, talvez não seja exagerada a expressão de que "o código binário se transforma numa relação social" (Vief, 1991, p. 134). $\mathrm{O}$ intercâmbio entre os bits transfigura a realidade em símbolos, de tal modo que as pessoas praticamente não têm outra opção a não ser se adaptar à linguagem binária. A expressão "eu ainda não me conectei", utilizada por aqueles que ainda não acessaram seus e-mails, ou então que não entraram nas suas respectivas comunidades do Orkut, desvenda a condição ontológica que predomina atualmente, pois uma existência sem a presença eletrônica torna-se uma não-existência viva (Türcke, 2002, p. 64). O próprio consumidor transforma-se numa mercadoria virtual avidamente disputada pela empresas da Internet, que oferecem todas as espécies de serviços e produtos associados em seus sítios (Garcia dos Santos, 2003, p. 130).

A supremacia da comunicação secundária sobre a primária não pode ser analisada, caso se desconsidere a forma como as relações de produção contemporâneas determinam as condiçōes nas quais ocorre tal heteronomia. De acordo com esta premissa, a análise das características dos programas de educação a distância deve se pautar pelo exame dos contextos históricos nos quais tais programas são aplicados. É isto que se pretende fazer mediante a investigação dos papéis dos agentes educacionais vinculados ao projeto Universidade Aberta do Brasil, em sua modalidade de ensino a distância.

\section{A Universidade Aberta do Brasil: educação a distância ou educação distante?}

Criado em 2005 pelo Ministério da Educação, o projeto da Universidade Aberta do Brasil (UAB) tem como principal objetivo articular e integrar "um sistema nacional de educação superior a distância, em caráter experimental, visando sistematizar as ações, programas, projetos, atividades pertencentes às políticas públicas voltadas para a ampliação e interiorização da oferta do ensino superior gratuito e de qualidade no Brasil". ${ }^{1}$ A premência de ações voltadas para a aplicação de recursos que incitem o incremento do ensino universitário situa-se fora de questão, sobretudo quando se considera o fato de que apenas $10 \%$ dos brasileiros de 18 a 24 anos têm acesso aos cursos de graduação nas universidades brasileiras. 
No bojo de tais ações, destaca-se a criação de um curso-piloto de Administração a distância, engendrado por meio de parecerias estabelecidas entre o Secretaria de Educação a Distância do MEC, o Banco do Brasil e várias instituições federais e estaduais de ensino superior. Tal curso terá a duração de quatro anos, sendo os três primeiros estruturados em base comum. Além disso, um ano será destinado às diferentes ênfases concernentes a este curso, as quais serão definidas pelas instituições ofertantes. $\mathrm{O}$ estudante será acompanhado por um processo de tutoria que permitirá, de acordo com os dizeres de tal projeto, "o monitoramento direto do desempenho e do fluxo de atividades, facilitando a interatividade e identificação de possíveis dificuldades de aprendizagem". ${ }^{2}$

Quando a discussão envereda para as formas de aplicação dos recursos para a difusão do ensino superior público e de qualidade no nosso país, o programa Universidade Aberta do Brasil surge, de acordo com a Secretaria de Educação a Distância do MEC, como uma alternativa primordial para viabilizar a formação universitária de $30 \%$ dos estudantes brasileiros até 2011. No âmbito geral, a dimensão de tal programa de educação a distância se distingue pela parceria entre os consórcios públicos dos três níveis governamentais (federal, estadual e municipal) e as universidades públicas e demais interessadas, de acordo com o sítio da UAB. Os municípios, cujas prefeituras se interessarem pelo programa de UAB, poderão se associar à Secretaria de Educação de seus respectivos estados e/ou Distrito Federal para a organização da infra-estrutura e do pessoal de apoio dos chamados pólos presenciais. O conceito de pólo presencial foi elaborado da seguinte forma: "Estrutura para a execução descentralizada de algumas das funções didático-administrativas de curso, consórcio, rede ou sistema de educação a distância, geralmente organizada com o concurso de diversas instituições, bem como com o apoio dos governos municipais e estaduais". ${ }^{3}$ A infra-estrutura dos laboratórios do Programa Nacional de Informática na Educação (PROINFO) poderá ser utilizada para a composição dos futuros pólos. Os recursos humanos concernentes à equipe técnica, administrativa e docente de cada pólo serão os seguintes: o coordenador do pólo, o técnico em informática, um bibliotecário, um auxiliar para a secretaria e os tutores presenciais.

Os pólos de apoio podem ser identificados, portanto, como elementos cruciais para o desenvolvimento do processo educacional/ formativo a distância. Nos locais escolhidos como pólos, os estudantes dos cursos superiores a distância terão acesso a bibliotecas, serão atendi- 
dos pelos tutores, assistirão às aulas e terão à sua disposição um laboratório de informática com recursos tecnológicos, tal com o uso da Internet, que lhes possibilitarão estudar os módulos dos respectivos cursos na forma de artigos e apostilas on line, por exemplo. Além de tais recursos, os pólos também terão salas para a secretaria acadêmica, para a coordenação do pólo, para os tutores, uma sala de professores e reunióes, uma sala de aula presencial típica e uma sala de videoconferência.

Os tutores presenciais serão contratados pelos municípios e deverão ter formação superior adequada às áreas específicas das disciplinas dos cursos. Já as universidades serão responsáveis pela formulação dos cursos, o que inclui a formação de uma equipe de professores que organizará o material didático, ministrará os conteúdos dos respectivos cursos por meio de recursos tecnológicos, tais como a Internet, os aparelhos que possibilitam a realização de videoconferências, fax, telefone etc., e orientará os tutores quanto à condução do projeto político-pedagógico dos cursos, de forma presencial ou não. É importante ressaltar que também as universidades privadas estão inseridas neste projeto, tal como pode ser observado na declaração do secretário de educação a distância do MEC, Ronaldo Mota: "Do consórcio das universidades públicas e não públicas, atuando em todos os Estados brasileiros, nós vamos formar um caldo cultural. Daí o surgimento da universidade aberta vai ser algo quase natural". ${ }^{4}$

Como se pode observar, trata-se de um projeto de grande envergadura e que se torna, de acordo com as pretensões governamentais, decisivo para seja a atingida a meta de que 30\% dos estudantes brasileiros tenham acesso à formação superior até o ano de 2011. É notória a importância do aumento do índice de estudantes universitários em um país, sobretudo quando se considera o real significado do processo educacional/formativo universitário e seus desdobramentos na produção do conhecimento tecnológico. Em meio à miríade de políticas educacionais patrocinadas pelo governo brasileiro, as quais se coadunam no objetivo de que seja arrefecida nossa defasagem universitária em relação a outros países, o programa Universidade Aberta do Brasil se diferencia não só pelos consórcios estabelecidos entre os três níveis governamentais, mas principalmente por se caracterizar como um programa de formação universitária na modalidade de educação a distância (EaD).

Dentre as várias formas de se definir o conceito de EaD, nota-se o elemento comum de que os agentes educacionais, separados espacialmente, se relacionam pela mediação de aparatos técnico-eletrônicos, tais como aqueles que foram citados na composição da infra-estrutura do programa 
Universidade Aberta do Brasil. O termo educação a distância parece conter uma contradição imanente que não pode passar despercebida e que suscita de imediato o aparecimento da seguinte questão: Pode um processo educacional/formativo ser desenvolvido a distância? Dito de outro modo: A despeito das bases epistemológicas e dos diversos métodos empregados nas situaçôes cotidianamente experimentadas nas salas de aula, o escopo central de tal processo não é o de proporcionar condições favoráveis para a aproximação e não para o distanciamento entre os professores e os alunos? Talvez o exemplo mais notório da possibilidade de aproximação entre os agentes educacionais e, não por acaso, ideal, foi o da relação estabelecida entre o preceptor Rousseau e seu aluno imaginário Emílio. A interação contínua entre ambos proporcionou a Emílio condiçōes de ler o livro do mundo, para se usar uma expressão do cartesiano Rousseau, pois o desenvolvimento de sua percepção dos objetos e das relações humanas lhe possibilitou, gradativamente, as habilidades para que fossem elaborados os seus primeiros juízos morais. A consciência de que a razão perceptiva sempre foi a base da razão intelectual se pautava no raciocínio dedutivo de que "Exercer os sentidos não é somente fazer uso deles, é aprender a julgar bem com eles, por assim dizer, a sentir; porque nós não sabemos nem apalpar, nem ver, nem ouvir senão da maneira que aprendemos" (Rousseau, 1992, p. 130).

A razão intelectual que não se esquiva do necessário "diálogo" com a razão perceptiva medeia as tensas relações entre força das paixões e as exigências sociais. Para Rousseau, a virtude nasce exatamente da capacidade de estabelecimento de tal "diálogo", que deve ser estimulado, mas não conduzido exclusivamente, pelo preceptor, de tal maneira que o aluno se sinta confiante em aceitar o desafio de dominar racionalmente suas vontades, sem que para isso precise lutar para solapá-las. O processo educacional/formativo de Emílio amealha, com o passar do tempo, a prerrogativa de ter se tornado um dos principais marcos da pedagogia moderna. $\mathrm{Ou}$ seja, pode-se questionar a recomendação de Rousseau de que o primeiro livro de Emílio seria Robinson Crusoé, mas há que se enfatizar a preocupação roussseauniana do respeito dos educadores quanto às diversas fases do desenvolvimento da criança. De fato, o filósofo francês elaborou uma crítica ácida à educação que vicejava na França e que, a seu ver, exigia que as crianças reproduzissem conceitos sem que soubessem seus respectivos significados. A promoção da denominada liberdade bem orientada, defendida por Rousseau, se contrapunha a este modelo de educação livresca, bem como exaltava o aluno que fosse capaz de equilibrar o exercício de sua vontade com as suas capacidades por meio da razão. Os princípios do exercí- 
cio da autonomia do aluno, constituída na relação de liberdade bem orientada pelo mestre, influenciaram decisivamente a concepção kantiana de que a autonomia "é o fundamento da dignidade da natureza humana e de toda a natureza racional” (Kant, 1995, p. 73). O deixar de ser menor e, portanto, de ser tutelado pelos mandos e desmandos de determinadas instituiçōes não se restringiu às prerrogativas do idealismo kantiano, pois a autonomia também se tornou uma categoria basilar da pedagogia. Para que o conceito de práxis educativa, proposto por Paulo Freire, se concretizasse, seria necessário que os oprimidos deixassem de hospedar o opressor dentro de si e que substituíssem a sombra dos opressores por outro conteúdo: o de sua autonomia (Freire, 1979, p. 35).

A palavra autonomia vai desenvolvendo novos avatares e hoje parece ser a palavra de ordem das propostas de educação a distância, pois o principal objetivo é o de facilitar o desenvolvimento da chamada aprendizagem autônoma. Neste tipo de aprendizagem, o professor precisa assumirse como recurso do aluno, uma vez que tal processo é centrado no aprendente, que é identificado e se identifica como indivíduo autônomo e administrador dos conhecimentos adquiridos. Não por acaso, vários pesquisadores de EaD adjudicam a utilização dos recursos midiáticos como o eixo norteador que facilitará o trabalho dos professores, e dos alunos que se tornarão mestres, a aprender a aprender (Mercado, 1999, p. 105), ou então de se transformarem em professores reflexivos (Alarcão, 2005, p. 25). Nesse sentido, os professores devem ser formados e, principalmente, se formar num ambiente educacional que valorize o exercício da criatividade e da reflexão como fundamentos da condição de ser autônomo. Mas será este o ambiente hegemônico nos atuais programas de aplicação de EaD? É verdade que os altos índices de evasão não são "privilégio" dos programas de educação a distância, porém, tal fato não pode mitigar a relevância de se investigar as razōes objetivas e subjetivas deste fenômeno.

Não são poucas as pesquisas que alertam a respeito da predominância da aprendizagem passiva entre os alunos de tais programas, os quais absorvem, ao invés de elaborar, os conteúdos aprendidos e se sentem desestimulados a continuar os estudos (Belloni, 1999, p. 40). Quando se reflete a respeito da aplicação do programas de EaD no Brasil, retorna a questão sobre que tipo de proximidade pode ocorrer entre os agentes educacionais formados a distância. Num país como o nosso, cujo poder das imagens religiosas 5 foi gradativamente substituído pela força das imagens televisivas, durante o processo de consolidação da indústria cultural na ditadura militar, torna-se prioritária a reflexão sobre a permuta da autoridade 
pedagógica pelo autoritarismo da imagem. No livro de sugestivo título $A$ caminho de uma sociedade sem pai, Alexander Mitscherlich investiga, por meio de uma leitura psicossocial, as conseqüências psíquicas da gradativa perda das autoridades paterna e materna e, portanto, dos modelos de referência dos filhos. A criança se transforma num adulto que desempenha funções anônimas e também é dirigido por tais funções. Neste contexto social, no qual predomina a vida tecnificada, não é difícil "descobrir o recrudescimento das manifestações narcísicas e agressivas" (Mitscherlich, 2003, p. 338). Já Adorno assevera que, em tempos de indústria cultural hegemônica, a substituição da função de consciência moral do supereu por autoridades externas, descompromissadas e permutáveis pode engendrar "heteronomia, uma dependência de preceitos, de normas que escapam à racionalidade do indivíduo" (Adorno, 1971, p. 92).

Ora, o desejo de transformar o professor numa entidade coletiva não corrobora o risco de reforçar tal autoritarismo imagético? A liquefação da figura do professor, que se torna uma espécie de prestador de serviços ${ }^{6}$ (Belloni, op. cit., p. 82) ou mesmo um recurso para o aluno, ilustra, despudoradamente, o seu processo de coisificação. E neste contexto que o data show, ou seja, o show de dados, expressa não só o modo "adequado" de como se deve transmitir os conteúdos pedagógicos, como também a nova função do professor: o animador de espetáculos audiovisuais. A violência que se dissemina na fragmentação da forma e do conteúdo das imagens televisivas é expressão de uma sociedade cujas relações de produção se "esmeram" pela reprodução de relaçōes humanas fragmentadas. É necessário atentar, portanto, para os prováveis danos psicológicos que tal lastro social determina. De acordo com Philippe Quéau (1993, p. 98),

É preciso, sem dúvida, por outro lado, começar a inquietar-se com as conseqüências psicológicas que um excessivo consumo de universos virtuais cria. Uma tendência à desrealização toma todas as pessoas que se apegam demasiadamente à perfeição limpa das matemáticas ou ao rigor lúdico da informática. A tecnologia da simulação virtual não pode senão reforçar este risco de desrealização, ao dar um caráter pseudoconcreto e pseudopalpável a entidades imaginárias.

Mas os professores que assumem a responsabilidade de organizar e transmitir os conteúdos das disciplinas dos cursos de formação de futuros educadores não são entidades imaginárias. Entretanto, são profissionais que podem se transformar numa caricatura autoritária de si próprios, não porque queiram fazê-lo, mas sim pela dimensão que a imagem televisiva assu- 
Educação a distância ou Educação distante? O Programa Universidade Aberta...

me quando não apenas representa a verdade, mas parece se tornar $a$ própria. A autoridade indevida, que os pacotes pré-preparados (Belloni, 1999, p. 44) dos materiais dos cursos a distância exercem sobre os alunos, deve ser compreendida também como fenômeno de uma sociedade que atualiza, por meio de suas forças produtivas tecnológicas, o dito do filósofo Berkeley (1992, p. 13) de que o ser dos objetos é ser percebido. E tal condição ontológica não se limita aos objetos, mas também se aplica às pessoas, pois o exibir-se adquire a força de um imperativo categórico: "A presença das luzes e das câmeras age como um imperativo diante do qual ninguém poderia recusar-se, como se estivesse diante de um torturador a quem conviria confessar tudo, inclusive o que não se fez" (Melman, 2003, p. 23).

As imagens de pessoas e objetos, convertidos em ícones fugazes, travam uma luta titânica entre si com a intenção de permanecer alguns momentos a mais na memória antes de serem pulverizadas e substituídas pelas imagens de "novos" ícones. E se esta lógica parece imperar quando nos deparamos com as imagens midiáticas, não seria muita pretensão acreditar que o professor estivesse isento de se tornar um destes ícones, quando os conteúdos de suas disciplinas são transmitidos tanto pela televisão quanto pela tela do computador? Uma questão como esta conduz o raciocínio para a análise dos papéis dos professores e dos tutores presencias, os quais mediam a relação pedagógica entre os professores virtuais de cada disciplina do curso de pedagogia, por exemplo, e seus alunos.

Um dos grandes desafios em relação ao ensino a distância é o de fornecer condições para que os professores ausentes se tornem presentes. Não se pode ser ingênuo a ponto de se acreditar que a presença física do professor garanta por si só o ensino de boa qualidade, haja vista o fato de prevalecer, em muitas ocasióes presenciais, o denominado pacto da mediocridade, no qual o professor finge que ensina e os alunos fingem que aprendem. Por outro lado, este imperativo categórico do exibir-se, que se aferra na atual condição ontológica de que ser é ser percebido, deve se tornar, necessariamente, objeto de crítica dos professores cujas imagens são filtradas pelos canais de transmissão dos aparelhos eletrônicos envolvidos no ensino a distância.

$\mathrm{Na}$ verdade, a presentificação do professor se faz, paradoxalmente, por meio de sua "virtualização", ou seja, pela possibilidade de se espicaçar o desenvolvimento de um número cada vez maior de representações que estimulem os alunos a questionar os conteúdos transmitidos, os quais, ao invés de serem absorvidos, podem ser elaborados criticamente. 
Pôde-se observar anteriormente o peso histórico que as palavras tutela, tutoria e tutor portam consigo. Nomes como Descartes, Galileu e, principalmente, Kant se destacaram pela produção de textos que, a despeito de seus objetivos díspares, se aproximaram pela defesa do pensamento e da intervenção livres dos obstáculos promovidos pela Igreja. "Vivemos numa época esclarecida?", indagava Immanuel Kant no seu texto: Resposta à pergunta: que é Esclarecimento?. Não, vivemos numa época em processo de Esclarecimento (Aufklärung), responde o filósofo alemão em 1783. Para que se pudesse abandonar o estado de menoridade, ou seja, o estado de ser tutelado por alguém, era preciso ousar saber e ter a coragem se fazer "uso do próprio entendimento" (Kant, op. cit., p. 100). Mas, em tempos do ensino a distância, mediado por tais tecnologias, os rumos do Esclarecimento parecem encaminhar o processo educacional/formativo ao encontro de uma incrível ironia. Diferentemente do século 18, no qual era vital o questionamento da presença da tutoria exercida pela Igreja, a atual presença do tutor, no processo de se educar a distância, torna-se imprescindível. $\mathrm{O}$ tutor não pode simplesmente absorver os conhecimentos transmitidos pelos professores, quer seja nos encontros presenciais esporádicos entre ambos, quer seja no sortilégio que as imagens de tais mestres "virtuais" possam exercer. Ele deve se permitir, cada vez mais, ousar saber, o que implica não a aceitação passiva dos conhecimentos obtidos, mas sim o questionamento destes mesmos conhecimentos.

O risco da chamada transformação do professor numa entidade coletiva, um termo muito apreciado pelos pesquisadores de educação a distância, é o de pulverizar a autoridade de tal professor a ponto dela se rearticular na forma do autoritarismo imagético que arrefece o desenvolvimento das representações e, portanto, do raciocínio crítico. É por isso que a ditadura das imagens, bem como o contexto histórico no qual ela se realiza devem ser criticados justamente por aqueles que se preocupam com os caminhos e descaminhos do processo educacional/formativo virtual. Nunca é em vão recordar que a comunicação primária precisa ser hegemônica em relação à secundária, a não ser que nos habituemos com o processo de fetichização e "decidamos" referendar nossa servidão voluntária, uma vez que nos identificamos como recursos ao invés de lutarmos, na medida do possível, para nos tornar sujeitos, ou seja, interventores de nossas ações. Não por acaso, os programas de educação a distância que obtiveram resultados positivos foram aqueles que tiveram êxito de aproximar, presencialmente, os agentes educacionais por meio das mediações técnicas. Ao co- 
Educação a distância ou Educação distante? O Programa Universidade Aberta...

mentar algumas experiências em EaD e seus resultados obtidos, Belloni (1999, p. 47) observa a freqüência, entre os estudantes, da

exigência de retorno imediato da informação, o que explica a receptividade a mídias interativas (telefone, e-mail); do desejo de encontrar outros estudantes, o que permite comparar dificuldades e discutir sobre a qualidade dos cursos; da necessidade de encontrar pessoalmente os tutores.

A necessidade do encontro presencial desvela aquela privação que foi distinguida anteriormente e que, na verdade, pode ser identificada como a força que impulsiona os indivíduos a desenvolver a tecnologia que os capacite a se aproximar de modo efetivo. É neste sentido que as manifestações técnicas podem contribuir para a transformação da razão perceptiva em razão intelectual, tal como diria Rousseau. Este jogo dos sentidos, que ocorre entre os agentes educacionais, de tal maneira que o olhar como que fala ao se expressar, fertiliza o solo da formação não só dos interesses dos alunos, como também de seus juízos morais. Se esta observação estiver correta, os tutores presenciais não podem ser identificados e se identificar como recursos, mas sim como profissionais que têm um papel decisivo no processo educacional/formativo a distância.

Dentre as críticas pertinentes elaboradas pelos pesquisadores que defendem a utilização dos recursos tecnológicos para a difusão do ensino a distância, sobressai-se a de que os professores recusam tal processo educacional/formativo, pois temem perder seus empregos ou então evitam a todo custo o aprendizado técnico exigido para o manuseio de tais recursos (Minoli, 1996, p. 10). Este temor, às vezes transformado em pavor, foi rotulado como tecnofobia. Tal designação não é exclusiva de nosso tempo. Marx (1988, p. 45) já destacara a revolta de trabalhadores ingleses contra uma serraria movida a vento no final do primeiro terço do século XVII. Gramsci (1974, p. 146) também criticou os sindicatos operários americanos que negavam os pressupostos do industrialismo, pois defendiam a manutenção de seus privilégios corporativos. Mas tanto Marx quanto Gramsci tinham plena consciência de que a produção técnica é produto do trabalho humano e que, como tal, deveria ser reapropriada justamente pelos explorados, que foram os responsáveis pelas condições materiais de sua produção. Ademais, ambos foram contrários a, digamos, jogar a criança junto com a água suja do banho, pois sabiam que negar a produção técnica como fruto do trabalho humano seria o mesmo que admitir a impossibilidade de se utilizar o potencial emancipatório da própria técnica para a conver- 
são histórica do reino da necessidade no reino da liberdade. Seguindo esta linha de raciocínio, a crítica da tecnofobia acerta no seu diagnóstico de que não se deve impedir o progresso das forças produtivas, espelhado no aperfeiçoamento tecnológico, mas se equivoca quando, aprioristicamente, considera que o uso da técnica depende exclusivamente do livre arbítrio de quem a "controla", a despeito, portanto, do contexto social no qual tal técnica foi ou é produzida.

\section{Conclusão}

A hegemonia de uma visão fetichizada dos recursos empregados no processo educacional/formativo a distância encontra sua simetria na chamada pulverização da autoridade pedagógica, a qual não pode ser imputada exclusivamente ao desenvolvimento das tecnologias comunicacionais, embora possa ser por elas potencializada. É verdade que, atualmente, as imagens disputam entre si uma maior sobrevida antes de serem estilhaçadas por outras mais espetaculares. Porém, mesmo nesta sociedade, não seria possível que os mestres ausentes utilizassem os aparatos técnico-eletrônicos para poder criticar e tensionar o próprio autoritarismo de sua imagem e, assim, pudessem se tornar mais presentes? Penso que sim. Mas, para que o conhecimento produzido seja discutido e modificado coletivamente, é necessário que a autoridade pedagógica seja "superada", o que não significa a sua eliminação. Quando os alunos percebem que suas opiniōes são respeitadas pelos mestres, inicia-se o processo de superação da autoridade pedagógica, pois as explicaçôes dos professores se conservam modificadas nas intervençôes do corpo discente. O Zaratustra, de Nietzsche, provoca seus sequazes da seguinte maneira: "Retribui-se mal um mestre quando se permanece sempre e somente discípulo. E por que não quereis arrancar folhas da minha coroa?” (2005, p. 105).

Será que este ímpeto cobrado por Zaratustra tende a se ausentar nas relaçôes estabelecidas pelos agentes educacionais, cujo processo educacional/formativo se realiza pela mediação de aparatos técnico-eletrônicos? Longe de ser inocente, o atual linguajar empregado em geral nos textos sobre educação a distancia prima pela associação da imagem do professor como um mensageiro, um recurso ou mesmo um prestador de serviços pedagógicos. O emprego de tais predicados denota a existência do fetiche tecnológico que se baliza na supremacia da comunicação secundária sobre a primária, de tal modo que há hoje o sério risco de revitalização do conhe- 
Educação a distância ou Educação distante? O Programa Universidade Aberta...

cido e malfadado tecnicismo pedagógico. Será que a ciência permanecerá e os homens continuarão a passar?

O anseio legítimo de se incrementar os índices do ensino universitário brasileiro não pode ser instrumentalizado, a ponto de novas estatísticas mais alentadoras obnubilarem os danos decorrentes no processo educacional/formativo. Na leitura da caracterização dos pólos presenciais no sítio do programa Universidade Aberta do Brasil, nota-se a presença de uma descrição pormenorizada dos elementos que compõem a infra-estrutura física de tais pólos, ao mesmo tempo em que tal presença contrasta com a ausência de uma posição que, ao menos, incite o início da discussão sobre temas tais como: Que tipo de relação pedagógica pode ser promovido entre os agentes educacionais envolvidos num processo de educação a distância? Que poder a imagem exerce na chamada sociedade do espetáculo? Como se desenvolve a relação entre autoridade pedagógica e autoritarismo num ambiente de aprendizagem virtual? Questôes como estas não podem ser evitadas, caso prevaleça o desejo de que a educação a distancia, ao invés de apartar os agentes educacionais, contribua para uma maior aproximação, justamente porque não se furta da necessidade de comunicar as privaçôes e alegrias humanas que a engendraram.

Recebido e aprovado em agosto de 2006.

Notas

1. Disponível em: <http://www.uab.mec.gov.br>

2. Disponível em: <http://www.uab.mec.gov.br/cursopiloto.php>

3. Disponível em: <http://www.uab.mec.gov.br/polo.php>

4. Disponível em: <http://www1.folha.uol.com.br/folha/educacao/ult305ul7362.shtml>

5. É importante observar que a própria religião necessariamente se adequa à lógica da indústria cultural, haja vista os casos do padre Marcelo Rossi, da Igreja Católica, ou o chamado "Show da fé", da Evangélica.

6. Uma designação bastante simpática ao capitalismo transnacional.

Referências bibliográficas

ADORNO, T.W. Erziehung nach Auschwitz. In: Adorno, T.W. Erziehung zur Mündigkeit. Frankfurt am Main: Suhrkamp Verlag, 1971.

ADORNO, T.W. Teoria da semicultura. Trad. Newton Ramos-de-Oli- 
veira, com a colaboração de Bruno Pucci e Cláudia de Moura Abreu. Educação \& Sociedade, Campinas, ano 17, n. 56, p. 388-412, dez. 1996.

ALARCÃO, I. Professores reflexivos em uma escola reflexiva. São Paulo: Cortez, 2005.

ANDERS, G. Die Antiquiertheit des Menschen I. München: C.H. Beck, 2002.

BACON, F. Novum organum. Trad. José Aluysio Reis de Andrade. São Paulo: Abril, 1973. (Coleção "Os pensadores")

BELLONI, M.L. Educação a distância. Campinas: Autores Associados, 1999.

BERKELEY, G. Tratado sobre os princípios do conhecimento humano. Trad. Antonio Sérgio. In: Berkeley \& Hume. São Paulo: Nova Cultural, 1992. (Coleção "Os pensadores")

BRAVERMAN, H. Trabalho e capital monopolista: a degradação do trabalho no século XX. Trad. Nathanael C. Caixeiro. Rio de Janeiro: Guanabara, 1987.

FOLHA Online. Disponível em: <www1.folha.uol.com.br/folha/ educacao/ult305ul7362.shtml>. Acesso em: 8 ago. 2006.

FREIRE, P. Pedagogia do oprimido. Rio de Janeiro: Paz \& Terra, 1979.

GARCIA DOS SANTOS, L. Politizar as novas tecnologias: o impacto sócio-técnico da informação digital e genética. São Paulo: Editora 34, 2003.

GRAMSCI, A. Obras escolhidas. Trad. Manuel Braga da Cruz. Lisboa: Estampa, 1974. vol. II.

GRUSCHKA, A. Bürgeliche Kälte und Pädagogik. Wetzlar: Büsche der Pandora, 1994.

HÖLDERLIN, F. Poemas. Trad. Paulo Quintela, Lisboa: Relógio d' Água, 1991.

KANT, I. Fundamentação da metafísica dos costumes. Trad. Paulo Quintela. Porto: Porto Editora, 1995.

KANT, I. Resposta à pergunta: que é Esclarecimento. In: Textos seletos. Edição bilíngüe. Trad. Raimundo Vier e Floriano de Souza Fernandes. Petrópolis: Vozes, 1985. 
Educação a distância ou Educação distante? O Programa Universidade Aberta...

MARX, K. O capital. Trad. Regis Barbosa e Flávio R. Kothe. São Paulo: Nova Cultural, 1988. vol. II.

MERCADO, L.P.L. Formação continuada de professores e novas tecnologias. Maceió: EDUFAL/COMPED/INEP, 1999.

MELMAN, C. O homem sem gravidade: gozar a qualquer preço. Trad. Sandra Regina Felgueiras. Rio de Janeiro: Companhia de Freud, 2003. MINISTÉRIO da Educação/Universidade Aberta do Brasil. Disponível em: <www.uab.mec.gov.br>. Acesso em: 15 jul. 2006.

MINISTÉRIO da Educação/Universidade Aberta do Brasil. Disponível em: <www.uab.mec.gov.br/polo.php>. Acesso em: 15 jul. 2006.

MINISTÉRIO da Educação/Universidade Aberta do Brasil. Disponível em: $<$ http://www.uab.mec.gov.br/cursopiloto.php>. Acesso em: 8 ago. 2006.

MINOLI, D. Distance learning technology and applications. Boston; London: Artech House, 1996.

MITSCHERLICH, A. Auf dem Weg zur vaterlosen Gesellschaft. Weinheim; Basel; Berlin: Beltz, 2003.

NIETZSCHE, F. Assim falou Zaratustra. Trad. Mário da Silva. Rio de Janeiro: Civilização Brasileira, 2005.

POSTMAN, N. O desaparecimento da infância. Trad. Suzana Menescal de Carvalho e José Laurenio de Melo. Rio de Janeiro: Graphia, 2005.

QUÉAU, P. O tempo do virtual. Trad. Henri Gervaiseau. In: PARENTE, A. (Org.) Imagem máquina: a era das tecnologias do virtual. São Paulo: Editora 34, 1993.

ROUSSEAU, J.J. Emílio ou da educação. Trad. Sérgio Milliet. Rio de Janeiro: Bertrand Brasil, 1992.

SENNETT, R. A corrosão do caráter: conseqüências pessoais do trabalho no novo capitalismo. Trad. Marcos Santarrita. Rio de Janeiro; São Paulo: Record, 2004.

TÜRCKE, C. Erregte Gesellschaft: philosophie der sensation. München: C.H. Beck, 2002.

VIEF, B. Digitales Geld. In: RöTZER, F. (Org.). Digitaler Schein: Ästhetik der elektronischen Medien. Frankfurt am Main: Suhrkamp, 1991. 